\title{
Coronary Risk Factors and Collateral Circulation in Acute Myocardial Infarction
}

\author{
Sheila Sumargo, ${ }^{1}$ Julius B. Dewanto, ${ }^{2}$ Syarief Hidayat ${ }^{3}$ \\ ${ }^{1}$ Faculty of Medicine Universitas Padjadjaran, ${ }^{2}$ Department of Biochemistry and Molecular \\ Biology Faculty of Medicine, Universitas Padjadjaran, ${ }^{3}$ Department of Cardiology and Vascular \\ Medicine Faculty of Medicine Universitas Padjadjaran/Dr. Hasan Sadikin General Hospital \\ Bandung
}

\begin{abstract}
Background: Coronary arterial stenosis, the major cause of acute myocardial infarction (AMI), induces shear stress to surrounding arteriolar endothelium. This stimulates changes in endothelial cells, smooth muscle cells and fibroblast to create collaterals that can provide alternative blood flow to the jeopardized myocardial area. However, coronary collateralization is various among AMI patients. The aim of this study was to analyze the correlation between coronary risk factors and collateral sirculation in AMI patients.

Methods: A retrospective cross-sectional study was carried out to 148 medical records of hospitalized AMI patients in Dr. Hasan Sadikin General Hospital Bandung, Indonesia. All patients were assessed for coronary collateral circulation which were graded as good (Rentrop score 2-3) and poor (Rentrop score 0-1). Risk factors noted in this study were age group, sex, hypertension, diabetes mellitus and diagnosis (ST-segment Elevation Myocardial Infarction (STEMI) or Non STEMI (NSTEMI)) according to the medical record data. Results: Hypertension was found to be associated with the presence of good coronary collateral circulation ( $p=0.02, P R=1.410$ [95\% CI 1.030-1.930]). Sex, age group, diabetes mellitus and STEMI or NSTEMI diagnosis were not statistically significant.

Conclusions: Hypertension was the only coronary risk factor associated to the presence of well-developed coronary collaterals. The increase of myocardial oxygen demand and flow of collateral feeding coronary artery in the setting of hypertension may contribute to the results. [AMJ.2015;2(4):529-33]
\end{abstract}

Keywords: Acute myocardial infarction, coronary collateral, coronary risk factors

\section{Introduction}

The majority of acute myocardial infarction (AMI) is caused by coronary arterial occlusion which leads to the death of myocytes. ${ }^{1}$ Age, sex, hypertension and diabetes mellitus are some important risk factors to the development of AMI. ${ }^{1}$ The type and the nature of coronary occlusion also determine how AMI develops, whether it is ST-segment Elevation Myocardial Infarction (STEMI) or Non STEMI (NSTEMI). ${ }^{2}$ The presence of spontaneous coronary collaterals may be able to limit the expansion of infarction area, since they provide alternative blood flow to the threatened myocardium. 3 The presence of functional coronary collaterals potentially lowers the infarct size, the development of heart failure and mortality rate after AMI, thus is accountable for better prognosis. ${ }^{4,5,6}$ The development of coronary collaterals involves the arteriogenesis process, which is the arterial defense mechanism against the intermittent and gradual occlusion of the culprit artery. ${ }^{7}$ Sudden arterial stenosis creates larger interarterial pressure gradient between arteries proximal and distal from it, inducing shear stress to surrounding arteriolar endothelial cells. ${ }^{1,8}$ This will stimulate arteriolar endothelial cells, smooth muscle cells and fibroblast leading to their remodeling to create larger collateral arteries that can provide alternative blood flow to the jeopardized myocardial area. ${ }^{9}$

However, the presence of coronary collateral circulation among AMI patients is various and the determinants of this discrepancy remain

Correspondence: Sheila Sumargo, Faculty of Medicine, Universitas Padjadjaran, Jalan Raya Bandung-Sumedang Km.21, Jatinangor, Sumedang, Indonesia, Phone: +62 81322230320 Email: sheilasumargo@gmail.com 
controversial. This phenomenon is suspected to be the cause of the differences in AMI risk factors. This study was undertaken to assess whether coronary risk factors were associated with the presence of well-developed coronary collateral vessels.

\section{Methods}

A retrospective cross-sectional study was carried out in Dr. Hasan Sadikin General Hospital Bandung Indonesia from MayNovember 2013 using medical records of all hospitalized patients diagnosed with AMI and underwent coronary angiography from January to December 2012. Out of 276 medical records selected, 128 medical records were excluded since data of thepatients did not meet the inclusion criteria (history of old myocardial infarction, history of previous elective Percutaneous Coronary Intervention (PCI), history of previous Coronary Artery Bypass Graft (CABG), and missing medical record data). One hundred and forty eight medical records were enrolled to the final study population. This investigation obtained permission from the institutional ethics committee and all data regarding patients were concealed.
The data of patients were classified according to the presence of visually apparent coronary collaterals in angiogram. Coronary angiograms of the patients were evaluated and next, collaterals were $t$ scored based on Rentrop classification which were then further classified as good (Rentrop score 2-3) and poor (Rentrop score $0-1$ ) coronary collaterals. The Rentrop score description is as follow; score 0 : no collaterals were visible; score 1: only side branches, but no major trunk, were visualized through collaterals; score 2: partial filling of the epicardial segment of the stenosed artery through collaterals; score 3: complete filling of the epicardial segment. ${ }^{10}$ The clinical risk factors noted from the patients were sex, age, hypertension, diabetes mellitus and diagnosis of AMI (STEMI and NSTEMI) based on the medical record data. Age was then divided into two groups with the median age of patients as the cutoff point. Other risk factors were not analyzed due to incomplete medical record data.

All data were analyzed by using the computer based Statistical Product and Service Solutions (SPSS) version 20.0. Furthermore, Chi-square test was used to compare categorical variablesand the $p$-value $<0.05$ was considered statistically significant.

Table 1 Baseline Characteristics of Study Patients

\begin{tabular}{lcc}
\multicolumn{1}{c}{ Clinical features } & $\begin{array}{c}\text { All patients } \\
\text { (n=148) }\end{array}$ & Percentage (\%) \\
\hline Mean age (years) & & 58.1 \\
Age group (n) & & \\
$\quad$ 58 years old & 75 & 50.7 \\
$>$ 58 years old & 73 & 49.3 \\
Sex (n) & & \\
$\quad$ Male & 125 & 84.5 \\
Female & 23 & 15.5 \\
Hypertension & & 62.8 \\
$\quad$ Yes & 93 & 37.2 \\
No & 55 & \\
Diabetes Mellitus & & 25.7 \\
Yes & 38 & 74.3 \\
No & 110 & \\
Diagnosis & & 77.0 \\
STEMI & 114 & 23.0 \\
NSTEMI & 34 & \\
\hline
\end{tabular}


Sheila Sumargo, Julius B. Dewanto, Syarief Hidayat : Coronary Risk Factors and Collateral Circulation in 531 Acute Myocardial Infarction

Table 2 Coronary Collaterals among Study Patients

\begin{tabular}{|c|c|c|c|c|}
\hline \multirow{2}{*}{ Clinical features } & \multicolumn{2}{|c|}{ Good collaterals } & \multicolumn{2}{|c|}{ Poor collaterals } \\
\hline & $(n=88)$ & Percentage (\%) & $(n=60)$ & Percentage (\%) \\
\hline Mean age (years) & \multicolumn{2}{|c|}{59.6} & \multicolumn{2}{|c|}{55.8} \\
\hline \multicolumn{5}{|l|}{ Age group (n) } \\
\hline$\leq 58$ years old & 40 & 45.5 & 35 & 58.3 \\
\hline$>58$ years old & 48 & 54.5 & 25 & 41.7 \\
\hline \multicolumn{5}{|l|}{$\operatorname{Sex}(n)$} \\
\hline Male & 73 & 83.0 & 52 & 86.7 \\
\hline Female & 15 & 17.0 & 8 & 13.3 \\
\hline \multicolumn{5}{|l|}{ Hypertension } \\
\hline Yes & 62 & 70.5 & 31 & 51.7 \\
\hline No & 26 & 29.5 & 29 & 48.3 \\
\hline \multicolumn{5}{|l|}{ Diabetes Mellitus } \\
\hline Yes & 26 & 29.5 & 12 & 20.0 \\
\hline No & 62 & 70.5 & 48 & 80.0 \\
\hline \multicolumn{5}{|l|}{ Diagnosis } \\
\hline STEMI & 65 & 73.9 & 49 & 81.7 \\
\hline NSTEMI & 23 & 26.1 & 11 & 18.3 \\
\hline
\end{tabular}

\section{Results}

From 148 patients, there were more patients diagnosed with STEMI than NSTEMI (Table 1). Table 2 shows that the study population was divided into 2 groups based on the coronary collateralization and there were more patients with good coronary collateral vessels (59.5\%).

Among the 148 study patients, there were more male than female. There were more patients in the $\leq 58$ years age group than in the $>58$ years age group. Over $60 \%$ patients were hypertensive, while only a quarter of study patients were found to have diabetes mellitus.

Table 3 shows that hypertension was significantly associated with the presence of better coronary collaterals $(\mathrm{p}=0.020$, $\mathrm{PR}=1.410$ [95\% CI 1.030-1.930]), however not for the younger age $(\mathrm{p}=0.124)$, male sex $(\mathrm{p}=0.541)$ and diabetes mellitus $(\mathrm{p}=0.192)$.

There were more patients with welldeveloped collaterals among STEMI patients $(n=65)$ and so were among NSTEMI $(n=23)$ patients (Table 2). However, there was no significant relationship between the presence of good coronary collaterals and the incidence of STEMI or NSTEMI $(\mathrm{p}=0.551)$ (Table 3$)$.

Table 3 Analysis of Coronary Collaterals Based on Clinical Features

\begin{tabular}{lcccc}
\hline \multirow{2}{*}{ Clinical features } & p-value & PR & Min & Max \\
\hline S 58 years old & & 0.779 & 0.570 & 1.066 \\
Male & 0.124 & 0.895 & 0.642 & 1.249 \\
Hypertension & 0.541 & 1.410 & 1.030 & 1.930 \\
Diabetes Mellitus & 0.020 & 1.214 & 0.925 & 1.593 \\
STEMI & 0.891 & 0.843 & 0.636 & 1.117 \\
\hline
\end{tabular}




\section{Discussions}

The study revealed that there was a significant relationship between hypertension and good collateralization. Age group, sex and diabetes mellitus were not associated with coronary collaterals development. A previous study corresponded with this finding. ${ }^{11}$ However, some studies pointed that a younger age, male sex and the absence of diabetes mellitus contributed to the development of better coronary collateral vessels. ${ }^{12,13,14}$ Additionally, age related endothelial dysfunction may contribute to the development of poor collaterals. ${ }^{12}$ While the ability of monocyte migration towards growth factor stimulation in diabetes mellitus was impaired, which contributes to poor collateralization in diabetic individuals. $^{14}$

There is also no significant difference in collateralization between STEMI and NSTEMI patients, as described in a previous study by Majumder et al. ${ }^{15}$ Thus the differences between the nature of coronary collaterals and pathophysiological process involving STEMI and NSTEMI may contribute to the result.

This study found that hypertension was associated to the development of better coronary collaterals $(\mathrm{p}=0.020, \mathrm{PR}=1.410[95 \%$ CI1.030-1.930]). This finding was in accordance with a previous study. ${ }^{16}$ The pathophysiology of hypertension involves the increase of heart rate and peripheral resistance, which leads to the augmentation of the cardiac workload and myocardial oxygen consumption. ${ }^{1}$ Chronic myocardial oxygen supply and demand imbalance contributes to the development of better coronary collateral circulation by increasing the expression of cytokine and growth factors needed to expand the coronary collaterals locally. ${ }^{17} \mathrm{~A}$ previous study by Meisel et al. ${ }^{16}$ stated that the systemic blood pressure determines the flow in the feeding coronary arteries supply collateral circulation which generates the pressure distal to occlusion. Thus, excessive lowering blood pressure in the setting of AMI may decrease the collateral flow and aggravate myocardial ischemia.16 This explained how hypertension can contribute to the development of better collateralization. Contrary to a previous study by Koerselman et al. ${ }^{18}$ which showed that hypertension is associated with poorer coronary collateralization. It showed that hypertension causes arteriolar remodeling which may lead to the obliteration of naturally occurred collateral arterioles. ${ }^{19,20}$ Nevertheless, certain limitations should be considered as history of risk factors treatments was not considered in this study. Furthermore, other variables such as other AMI risk factors (lipid profile, obesity or smoking), and their treatments as well as the degree of coronary occlusion, which might actually give better association with the development of collaterals, were not analyzed in the current study. The limited number of patients may also contribute to the study results.

This study showed that among coronary risk factors analyzed there is a significant association between hypertension and better coronary collateralization in the setting of AMI patients. The increase of myocardial oxygen demand and flow of the feeding coronary arteries supply collateral circulation in the setting of hypertensive state may contribute to the results.

\section{References}

1. Bonow RO, Mann DL, Zipes DP, Libby $\mathrm{P}$, Braunwald E, editors. Braunwald's heart disease: a textbook of cardiovascular medicine. $9^{\text {th }}$ ed. Philadelphia: Saunders Elsevier; 2012.

2. Daga LC, Kaul U, Mansoor A. Approach to STEMI and NSTEMI. J Assoc Physicians India. 2011;59 Suppl:19-25.

3. Ng S. Coronary collaterals: occurrence and functions [thesis]. Utrecht: Utrecht University; 2012.

4. Plein S, Younger JF, Sparrow P, Ridgway JP, Ball SG, Greenwood JP. Cardiovascular magnetic resonance of scar and ischemia burden early after acute st elevation and non-st elevation myocardial infarction. J Cardiovasc Magn Reson. 2008;10:47.

5. Steg PG, Kerner A, Mancini GBJ, Reynolds HR, Carvalho AC, Fridrich V, et al. Impact of collateral flow to the occluded infarctrelated artery on clinical outcomes in patients with recent myocardial infarction: a report from the randomized occluded artery trial. Circulation. 2010;121(25): 2724-30.

6. Meier P, Hemingway H, Lansky AJ, Knapp G, Pitt B, Seiler C. The impact of the coronary collateral circulation on mortality: a metaanalysis. Eur Heart J. 2011;33(5):614-21.

7. Hershey JC, Baskin EP, Glass JD, Hartman HA, Gilberto DB, Rogers IT, et al. Revascularization in the rabbit hindlimb: dissociation between capillary sprouting and arteriogenesis. Cardiovasc Res. 2001; 49(3):618-25.

8. Heil M, Schaper W. Influence of mechanical, 
cellular, and molecular factors on collateral artery growth (arteriogenesis). Circ Res. 2004;95(5):449-58.

9. Seiler C. The human coronary collateral circulation. Eur J Clin Invest. 2010;40(5): 465-76.

10. Tanboga IH, Topcu S, Nacar T, Aksakal E, Kalkan K, Kiki I, et al. Relation of coronary collateral circulation with red cell distribution width in patients with non-ST elevation myocardial infarction. Clin Appl Thromb Hemost. 2014;20(4):411-5.

11. Nathoe HM, Koerselman J, Buskens E, van Dijk D, Stella PR, Plokker THW, et al. Determinants and prognostic significance of collaterals in patients undergoing coronary revascularization. Am J Cardiol. 2006;98(1):31-5.

12. Kurotobi T, Sato $H$, Kinjo $K$, Nakatani D, Mizuno H, Shimizu M, et al. Reduced collateral circulation to the infarct-related artery in elderly patients with acute myocardial infarction. J Am Coll Cardiol. 2004;44(1):28-34.

13. Zorkun C, Akkaya E, Zorlu A, Tandogan I. Determinants of coronary collateral circulation in patients with coronary artery disease. Anadolu Kardiyol Derg. 2013;13(2):146-51.

14. Waltenberger J. Impaired collateral vessel development in diabetes: potential cellular mechanisms and therapeutic implications.
Cardiovasc Res. 2001;49(3):554-60.

15. Majumder A, Karim M, Rahman M, Uddin M. Study of association of c- reactive protein with coronary collateral development. Cardiovasc J. 2010;3(1):26-32.

16. Meisel SR, Frimerman A, Blondheim DS, Shotan A, Asif A, Shani J, et al. Relation of the systemic blood pressure to the collateral pressure distal to an infarctrelated coronary artery occlusion during acute myocardial infarction. Am J Cardiol. 2013;111(3):319-23.

17. Schirmer SH, van Royen N, Moerland PD, Fledderus JO, Henriques JP, van der Schaaf $\mathrm{RJ}$, et al. Local cytokine concentrations and oxygen pressure are related to maturation of the collateral circulation in humans. J Am Coll Cardiol. 2009;53(23):2141-7.

18. Koerselman J, Jaegere PPTd, Verhaar MC, Graaf Yvd, Grobbee DE. High blood pressure is inversely related with the presence and extent of coronary collaterals. J Hum Hypertens. 2005;19(10):809-17.

19. Humphrey JD. Mechanisms of arterial remodeling in hypertension: Coupled roles of wall shear and intramural stress. Hypertension. 2008;52(2):195-200.

20. de Marchi SF, Gloekler S, Meier P, Traupe T, Steck H, Cook S, et al. Determinants of preformed collateral vessels in the human heart without coronary artery disease. Cardiology. 2011;118(3):198-206. 